\title{
Semifinais das Olimpíadas de Química JúNIOR 2011
}

No passado dia 2 de Abril, realizaram-se por diversas cidades do país (Aveiro, Braga, Coimbra, Covilhã, Faro, Lisboa, Porto e Vila Real) as semifinais das Olimpíadas de Química Júnior. Este ano, a iniciativa contou com a participação de 487 equipas, correspondendo a um total de 1461 alunos, distribuídos da seguinte forma: 111 equipas participantes em Lisboa (Faculdade de Ciências da Universidade de Lisboa, Faculdade de Ciências e Tecnologia da Universidade Nova de Lisboa e Instituto Superior Técnico), 54 equipas no Porto (Faculdade de Ciências da Universidade do Porto), 82 equipas em Aveiro (Universidade de Aveiro), 33 equipas em Faro (Universidade do Algarve), 69 equipas na Covilhã (Universidade da Beira Interior), 61 equipas em Coimbra (Universidade de Coimbra), 41 equipas em Braga (Universidade do Minho) e 36 equipas em Vila Real (Universidade de Trás-os-Montes e Alto Douro).

Em cada semifinal foram premiadas as 3 melhores equipas, respectivamente com as medalhas de "Ouro", "Prata" e "Bronze". Segundo o regulamento, para a Final Nacional, são apuradas a equipa $1^{\text {a }}$ classificada de cada semifinal, mais a $2^{a}$ classificada das semifinais com mais participantes, até ao número máximo de 20 equipas. Os alunos apurados disputaram a $\mathrm{Fi}$ nal Nacional que decorreu no dia 7 de Maio de 2011 na Universidade de Trás-os-Montes e Alto Douro.

\section{Lista dos Vencedores}

\section{Escolas Vencedoras em Braga}

- Instituto Nun' Álvares, Santo Tirso

- Escola Básica dos $2 .^{\circ}$ e $3 .^{\circ}$ Ciclos de Caldas das Taipas, Guimarães

- Escola Básica dos $2 .^{\circ}$ e $3 .^{\circ}$ Ciclos Abel Salazar - Ronfe, Guimarães

\section{Escolas Vencedoras em Vila Real}

- Escola Básica dos $2 .^{\circ}$ e $3 .^{\circ}$ Ciclos D. Manuel de Faria e Sousa

- Escola Básica dos $2 .^{\circ}$ e $3 .^{\circ}$ Ciclos D. Manuel de Faria e Sousa

- Colégio "Nossa Senhora da Boavista"

\section{Escolas Vencedoras no Porto}

- Colégio de Ermesinde

- Escola Básica dos $2 .^{\circ}$ e $3^{\circ}$ Ciclos

Dr. Flávio Gonçalves

- Grande Colégio "Universal"

\section{Escolas Vencedoras em Aveiro}

- Escola Básica dos $2 .^{\circ}$ e $3 .^{\circ}$ Ciclos de Cacia

- Escola Secundária com 3. ${ }^{\circ}$ Ciclo do Ensino Básico de Sever do Vouga

- Escola Básica dos $2 .^{\circ}$ e $3 .^{\circ}$ Ciclos de Bento Carqueja

\section{Escolas Vencedoras em Coimbra}

- Escola Básica dos 2. ${ }^{\circ}$ e $3 .^{\circ}$ Ciclos de Frei Estevão Martins

- Escola Básica dos $2 .^{\circ}$ e $3 .^{\circ}$ Ciclos Prof. Alberto Nery Capucho

\section{Escolas Vencedoras na Covilhã}

- Escola Básica dos 2..$^{\circ}$ 3. Ciclos Serra da Gardunha (Fundão)

- Escola Básica dos $2 .^{\circ}$ e $3 .^{\circ}$ Ciclos da Cidade de Castelo Branco

Escolas Vencedoras em Lisboa

- Colégio "Vasco da Gama" (DQB/ FCUL)

- Escola Básica dos $2 .^{\circ}$ e $3 .^{\circ}$ Ciclos dos Castanheiros (DQB/FCUL)

- Colégio Marista de Carcavelos (DQB/FCUL)

- Escola Técnica e Liceal Salesiana de $\mathrm{St}^{\circ}$ António (DQ-FCT/UNL)

- Escola Secundária com $3 .^{\circ}$ Ciclo do Ensino Básico de Palmela (DQ-FCT/ UNL)

- Externato "Frei Luís de Sousa" (DQFCT/UNL)

- Escola Básica Integrada São Bruno (IST)

- Escola Secundária com 3. ${ }^{\circ}$ Ciclo do Ensino Básico de Stuart Carvalhais (IST)

- Colégio Infante Santo (IST)
Escolas Vencedoras em Faro

- Escola Básica dos $2 .^{\circ}$ e $3 .^{\circ}$ Ciclos de Santo António

- Escola Básica dos $2 .^{\circ}$ e $3 .^{\circ}$ Ciclos de D. Afonso III

- Escola Básica dos $2 .^{\circ}$ e $3 .^{\circ}$ Ciclos Dr. Francisco Cabrita - Albufeira

Semifinal das Olimpíadas de QuíMICA JÚNIOR NA UNIVERSIDADE DO MINHO

O Departamento de Química da Universidade do Minho organizou, pela sétima vez consecutiva, as Olimpíadas de Química Júnior em colaboração com a Sociedade Portuguesa de Química. No passado dia 2 de Abril de 2011 estiveram presentes no Campus de Gualtar, em Braga, 120 alunos provenientes de 39 escolas da região, organizados em 39 equipas, acompanhados por mais de 40 professores.

Após uma curta cerimónia de boas vindas a todos os participantes, as provas tiveram início às $14: 30 \mathrm{~h}$ nos laboratórios de ensino do Departamento de Química e no Anfiteatro da Escola de Ciências. Durante cerca de duas horas, as 39 equipas responderam a 24 questões na prova de laboratório, baseadas em situações e montagens experimentais e a outras 29 questões na prova de anfiteatro, baseadas em situações apresentadas com recurso a meios audiovisuais.

Pelas 17:00h todos os participantes tiveram oportunidade de assistir a uma palestra intitulada "Química: uma carreira" apresentada pela Doutora Sílvia Pereira Lima. Foram sorteados alguns brindes pelos alunos participantes e Professores acompanhantes (T-shirts com a Tabela Periódica, réguas, ca-
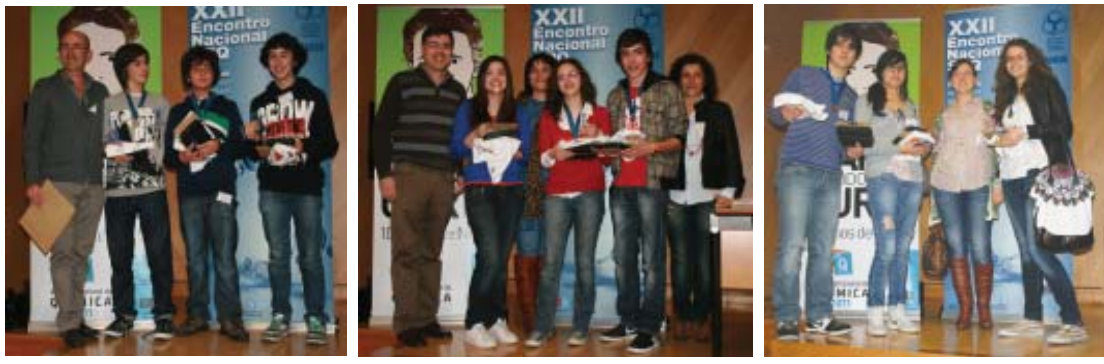

Equipas classificadas em $1^{\circ}, 2^{\circ}$ e $3^{\circ} \mathrm{s}$ lugares (da esquerda para a direita) na semifinal realizada na Universidade do Minho 
netas oferecidas pela UM e livros de Química oferecidos pela SPQ).

A divulgação dos resultados, momento alto das OQJ, aconteceu por volta das 17:30h. A medalha de ouro foi atribuída à equipa constituída pelos alunos Gonçalo Sampaio, Hernâni Cardoso e Telmo Silva, do Instituto Nun' Álvares, de Santo Tirso, acompanhada pelo Prof. Jorge de Sá Araújo. A medalha de prata foi entregue à equipa constituída pelos alunos Ana Catarina Ferreira, Ana Sofia Martinho e Nuno José Silva, da Escola EB 2,3 de Caldas das Taipas, de Guimarães, acompanhada pela Prof. Isabel Monteiro. A medalha de bronze foi para a equipa constituída pelos alunos Maria Margarida Mendes, Susana Matias e Pedro Oliveira, da Escola EB 2,3 Abel Salazar, de Guimarães, acompanhada pela Prof. Susana Matias. Para além das medalhas da SPQ, estes alunos foram presenteados pelo Departamento de Química da UM com T-shirts com a Tabela Periódica, caixas de modelos moleculares e vales-oferta FNAC, de valor variável consoante o lugar obtido.

Este evento contou com o patrocínio da SPQ, do Departamento de Química da Universidade do Minho e de algumas empresas. A cobertura das OQJ foi feita pelos órgãos de comunicação social da região e as fotos do acontecimento estão disponíveis em www.uminho.pt no item Comunicação, Fotos.

Maria Manuela Silva, Maria José Medeiros, Maria Gabriela Botelho, Maria Manuela Raposo, Susana Costa e Sílvia Lima

Comissão Organizadora das OQJ 2011 na Universidade do Minho

Semifinal das Olimpíadas de QuímiCA Júnior no Departamento de QuíMICA - FAC. CIÊnCIAS - U. PoRTO

As semifinais das Olimpíadas de Química Júnior 2011, realizaram-se, mais uma vez, nas instalações do Departamento de Química e Bioquímica da Faculdade de Ciências, da Universidade do Porto, no passado dia 2 de Abril de 2011, cabendo a sua organização a docentes deste Departamento. Concorreram para participar nesta prova
54 Escolas, tendo comparecido 46 escolas / 138 estudantes dos $8^{\circ}$ e/ou $9^{\circ}$ anos. Cada equipa acompanhada por um professor da respectiva Escola.

Após uma breve recepção informal, iniciaram-se as provas, compostas por algumas questões de carácter teórico, que decorreram num anfiteatro e outras de carácter mais experimental, montadas em cinco laboratórios. As equipas foram distribuídas por onze grupos acompanhadas por guias, alunos de Licenciatura em Química. A par das provas para os alunos, foi proporcionada a possibilidade de os seus professores participarem numa apresentação do portal da Casa das Ciências. Terminadas as provas houve um almoço na Cantina. De tarde realizou-se uma apresentação do Departamento de Química e Bioquímica bem como do curso de Química, pelo Prof. Cosme Moura, Vice Presidente do DQB. Seguiu-se o tão ansiado momento da divulgação dos resultados e distribuição dos prémios. Foram distribuídos diplomas de participação a todos os jovens e respectivos professores, bem como aos alunos do DQB que colaboraram no evento. Aos vencedores $\left(1^{\circ}, 2^{\circ}\right.$ e $3^{\circ}$ lugares) foram entregues medalhas, oferta da SPQ:

$1^{\circ}$ - Colégio de Ermesinde: Bernardo Teixeira, Henrique LasCasas e Joaquim Faria

$2^{\circ}$ - E.B com $2^{\circ}$ e $3^{\circ}$ ciclos Dr. Flávio Gonçalves: Andriy Bulenok, Filipe de Oliveira Castro e Gil Ferraz Maio Gonçalves

$3^{\circ}$ - Grande Colégio Universal: Dmitriry Moreira, Miguel Pinto e Pedro Pereira

A organização agradece à Reitoria da U.P. o apoio dado a esta iniciativa, bem como à Porto Editora e à Leya.

Ana Reis

Organização das OQJ 2011 no Porto
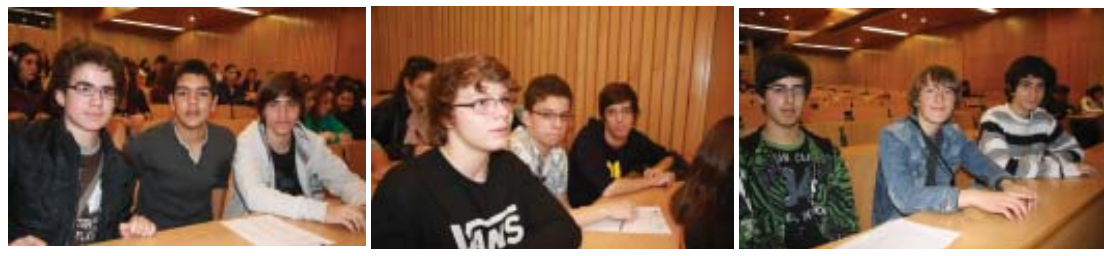

Alunos vencedores da semifinal realizada no Porto $\left(1^{\circ}, 2^{\circ}\right.$ e $3^{\circ} \mathrm{s}$ lugares, da esquerda para a direita)
Semifinal das Olimpíadas de QuíMICA JÚNIOR EM CoIMBra

Após termos tido a oportunidade de organizar, no ano anterior, as semifinais e finais das Olimpíadas de Química Júnior (OQJr), estávamos de volta para mais um ano, com mais umas olimpíadas no departamento de química da FCTUC. Já eram as sétimas!

No Ano Internacional da Química é natural que se queira dar um brilho especial a estas iniciativas. Mas, para nós, manter o nível já seria muito bom. E assim, este ano com a colaboração de muitos estudantes de pós-doc, doutoramento, mestrado, do núcleo de estudantes de química, do Brasil (os nossos PLI), e mais, muitos mais, num total de 30 elementos (incluindo um fotógrafo oficial da FCTUC!) lá pusemos de novo mãos à obra nas semanas anteriores e no próprio dia. $\mathrm{E}$ assim foi ver chegar, logo a partir das 8:30h, os nossos mais de 170 participantes, vindos de 42 escolas dos distritos de Coimbra, Viseu, Leiria, Santarém e Aveiro.

Depois da sessão de abertura onde, contando com as figuras institucionais (DQ, FCTUC e Reitoria), fazemos sempre um elogio à química $e$, mostrando fotos de anos anteriores, ilustramos o que irá acontecer durante as provas e no dia, iniciaram-se as provas que decorreram pela manhã. $\mathrm{Ne}$ las os alunos puderam efectuar, nos laboratórios do departamento de química, múltiplas actividades práticas e uma prova constando de perguntas com resposta de escolha múltipla. No final todas as equipas obtiveram classificações com uma média acima dos $70 \%$, sendo que os vencedores se situaram nos $98 \%$ !

Enquanto os nossos jovens "olímpicos" realizavam as suas provas, os professores realizaram um passeio químico pela Universidade e Jardim 
Botânico com o Prof. Sérgio Rodrigues. Depois, todos, professores e alunos, se reencontraram ao almoço (na cantina das químicas) onde puderam confraternizar e contar as histórias do dia.

Passado esse momento de ganhar energias e enquanto a organização corrigia as provas tivemos a Prof. Palmira Ferreira da Silva e a Dra. Raquel Dias a apresentarem uma animada palestra sobre "detectives químicos" onde a biologia se encontrou com a química e Alfred Hitchcock foi revisitado.

E por fim foi a altura do anúncio dos vencedores e da entrega dos prémios.

Em primeiro lugar ficou a equipa "Discípulos de Lavoisier" constituída pelos alunos António Barreiro, Beatriz Sousa, Hélvio Simões e orientada pelo Prof. Desidério Carreira Pires da Escola Básica dos $2 .^{\circ}$ e $3 .^{\circ}$ Ciclos de Frei Estevão Martins, Alcobaça.

O Prof. Desidério Carreira Pires, deve ser considerado um autêntico "case study" pois já conseguiu outras duas vitórias em semifinais (Coimbra) e também em duas finais nacionais!

O segundo lugar pertenceu também à mesma escola, equipa "Discípulos de Curie", composta pelos alunos Andreia Sofia da Silva Pereira, Bernardo Pereira Venceslau e João Maria Cunha Campos, igualmente orientada pelo Prof. Desidério Carreira Pires.

No terceiro lugar ficou a equipa "Isótopos", composta pelos alunos Adriana Órfão Nobre, Joana Luísa Ribeiro Santos, Manuel da Silva Santos e orientada pelo Prof. António Manuel Andrade Ferreira de Almeida, da Escola Básica dos $2 .^{\circ}$ e $3 .^{\circ}$ Ciclos Prof. Alberto Nery Capucho, Marinha Grande.

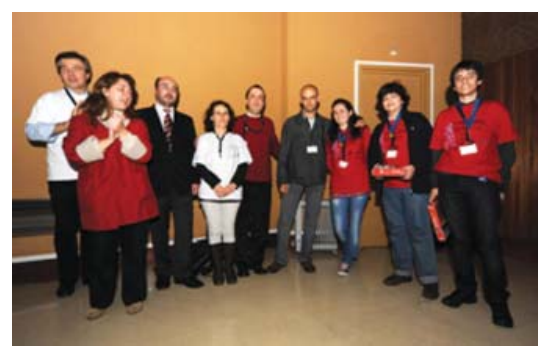

Os vencedores da semifinal realizada em Coimbra (do lado direito da foto) com o Professor Desidério Carreira Pires (ao centro), contando (à esquerda) com elementos da organização e com o presidente da FCTUC, o Prof. Luís Neves
Finalmente foi tempo de regressar a casa mas não sem antes poderem lanchar e conviver mais um pouco, desfrutando de uma magnífica vista da Universidade que se tem a partir do átrio do $2^{\circ}$ andar do nosso departamento.

A todos os que apoiaram e patrocinaram, CGD, FCTUC, Reitoria da UC, CMC, Porto Editora, o nosso reconhecimento pela ajuda que de uma forma geral tem sido continuada e generosa. Só assim se consegue que o entusiasmo e alegria possam manterse de ano para ano. A todos os participantes destas olimpíadas, o nosso muito obrigado pela vossa presença e entusiasmos. Àqueles que connosco colaboraram na organização das OQJr2011 um bem-haja e um sincero reconhecimento pelo esforço.

A todos um bom ano cheio de química. Até para o ano!

\section{João Sérgio Seixas de Melo e Maria} João Moreno

Organização das OQJ 2011 em Coimbra

\section{Semifinal das Olimpíadas de Quí- MICA JÚNIOR NA UBI (COVILHÃ)}

Pelo sétimo ano consecutivo decorreu no Departamento de Química da Universidade da Beira Interior uma semifinal regional das Olimpíadas de Química Júnior. A organização deste evento esteve a cargo das docentes Maria de Lurdes Franco Ciríaco e Maria José Alvelos Pacheco, tendo contado com a colaboração de outros docentes, funcionários não docentes e alunos dos $1^{\circ}$ e $2^{\circ}$ ciclos de estudos em Química Industrial, Bioquímica e Ciências Biomédicas. Este ano, o evento teve o patrocínio do banco BPI. O evento contou na sua sessão

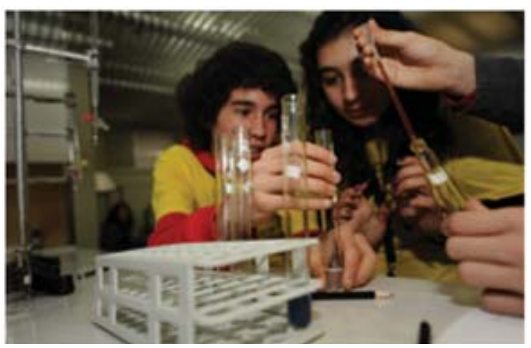

Equipa "Os isótopos"da escola Escola Básica 2/3 Professor Alberto Nery Capucho, Marinha Grande, que acabaria por ficar no $3^{\circ}$ lugar na semifinal realizada em Coimbra de abertura com a presença do Magnifico Reitor da UBI, Professor João Queiroz, que, acompanhado pela Presidente do Departamento de Química, Professora Isabel Ismael, e pela comissão organizadora deu as boasvindas aos participantes.

Nesta edição das OQJ participaram efectivamente 201 alunos, integrados em 68 equipas, provenientes de 21 escolas dos distritos de Castelo Branco, Guarda e Portalegre. Durante a manhã as equipas participantes realizaram duas provas com questões de escolha múltipla, uma de carácter mais teórico, que teve lugar no anfiteatro Prof. Pinto Peixoto, e outra de carácter experimental, que decorreu nos laboratórios de Química. Neste período, os professores acompanhantes tiveram ao seu dispor uma visita guiada a um dos núcleos do Museu de Lanifícios da Universidade da Beira Interior, o Núcleo da Real Fábrica Veiga/Centro de Interpretação dos Lanifícios. Seguiuse o almoço dos participantes na Cantina de Sto. António da UBI.

A cerimónia de encerramento teve início às 15:30h, com a actuação da EncantaTuna, uma das tunas femininas da UBI, que pela segunda vez cantou e encantou. Por fim, foram divulgados os resultados das provas e entregues as medalhas e os prémios BPI por representantes desta entidade bancária, o Sr. Rui Coelho, a Dra Cristina Silva e o Dr. Miguel Silva. Os premiados receberam ainda lembranças da UBI, da Casa da Lagariça e da Rotoquímica. $\mathrm{O}$ evento encerrou com um lanche convívio no Bar do pólo I da Universidade da Beira Interior.

$1^{\circ}$ Lugar - Medalha de Ouro: Mariana Carvalho Fernandes, Nuno Miguel

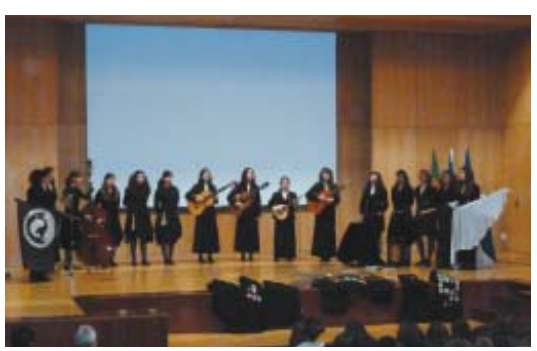

Ambiente da Semifinal das OQJ na UBI 
Brito Fontes, Rafaela Sofia de Oliveira Pires (Escola Básica Serra da Gardunha, Fundão)

$2^{\circ}$ Lugar - Medalha de Prata: Diogo do Espírito Santo Moreno, João Filipe Alves Reis, Mariana Cunha Reis Sebastião David (Agrupamento de Escolas Cidade de Castelo Branco, Castelo Branco)

$3^{\circ}$ Lugar - Medalha de Bronze: Madalena João da Cruz Antunes, Rodrigo de Oliveira Baptista, Rodrigo Filipe Salgueiro Martins Policarpo (Agrupamento de Escolas Cidade de Castelo Branco, Castelo Branco)

\section{Lurdes Ciríaco e Maria José Pacheco}

Organização das OQJ 2011 na Covilhã

\section{Semifinal das Olimpíadas de Quí-} MICA JÚNIOR NA UTAD (VILA ReAL)

Em Vila Real, as provas decorreram durante a tarde nos laboratórios do edifício do complexo pedagógico da UTAD e consistiram na resolução de questões baseadas em observações e manipulações de experiências adequadas aos currículos dos $8^{\circ}$ e $9^{\circ}$ anos de escolaridade. $\mathrm{O}$ evento reuniu 22 escolas de vários concelhos da Região Norte num total de cerca de 100 alunos que se mostraram muito entusiasmados e participativos. Nesta edição, os três primeiros lugares foram conquistados pelas seguintes equipas:

$1^{\circ}$ lugar - A equipa "Os Isótopos" constituída pelos alunos Joana Queirós, Jorge Gabriel e Marcelo Oliveira da Escola Básica dos $2^{\circ}$ e $3^{\circ}$ ciclos D. Manuel de Faria e Sousa, Felgueiras, orientada pelos Profs Luís Miguel Martins e Pedro Goucho.

$2^{\circ}$ lugar - A equipa "Os Radioactivos" constituída pelos alunos Ana Isabel

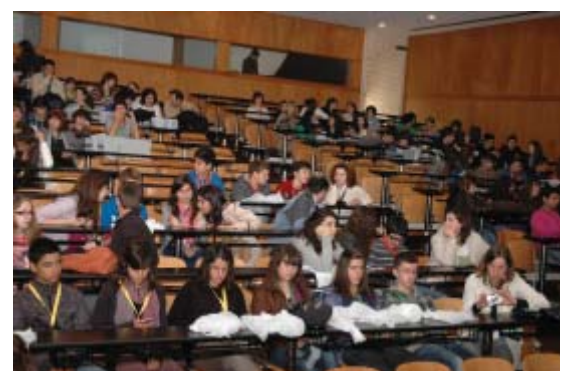

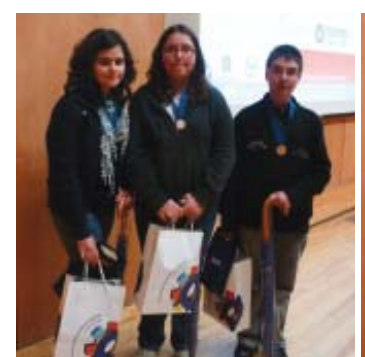
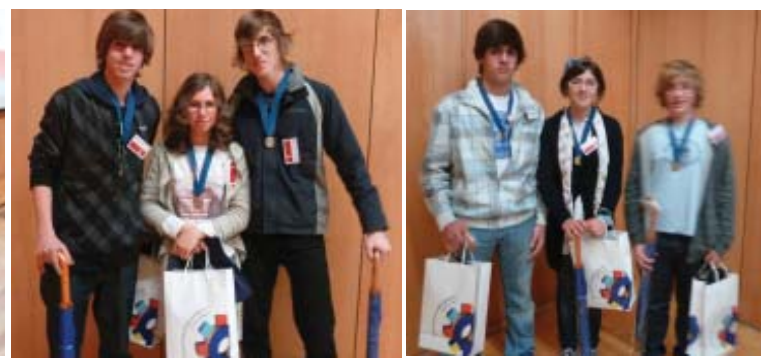

Equipas classificadas em $1^{\circ}, 2^{\circ}$ e $3^{\circ} \mathrm{s}$ lugares (da esquerda para a direita), na semifinal realizada na Covilhã

Batista, Érica Teixeira e Tiago Brito, também da mesma escola e orientada pelos mesmos professores (Escola Básica dos $2^{\circ}$ e $3^{\circ}$ ciclos D. Manuel de Faria e Sousa, Felgueiras, Profs Luís Miguel Martins e Pedro Goucho).

$3^{\circ}$ lugar - A equipa constituída pelos alunos Alexandre Portela, Diogo Vinagre e Emanuel Canelas, do Colégio Nossa Senhora da Boavista, Vila Real orientada pelos Profs Carlos Pires e Manuel João Soares.

Paralelamente às provas, decorreu o $1^{\circ}$ Workshop de Gastronomia Molecular, onde participaram os professores acompanhantes das equipas participantes das Olimpíadas e que contou com a preciosa colaboração de vários alunos do $2^{\circ}$ Ciclo em Biotecnologia de Qualidade Alimentar e de Bolseiros de Investigação do Centro de Química - Vila Real. Neste Workshop prepararam-se e testaram-se diversas iguarias, muito apreciadas por todos, tais como: Caviar de cores, Bombons Surprise Madame Curie, Explosion de mangue en fil, chantilly de chocolate e Fromage de fondue de olive. Esta iniciativa contou com o apoio da Reitoria da UTAD, da Escola das Ciências da Vida e do Ambiente e do Centro de Química de Vila Real e com o patrocínio da Minfo, Reagente-5 e Águas de Carvalhelhos.

Este ano, a UTAD acolheu ainda, no passado dia 7 de Maio, a prova final a

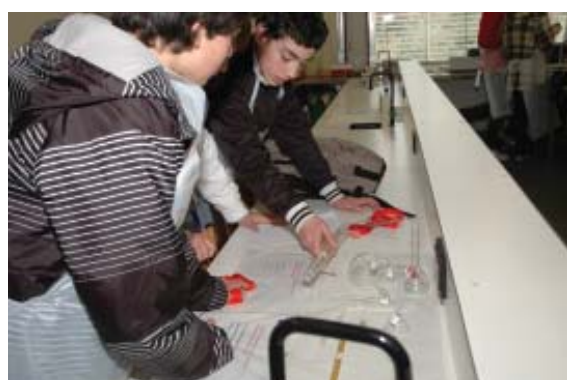

nível nacional, que contou com a participação de todas as equipas classificadas nos dois primeiros lugares das provas regionais. Nesse mesmo dia, teve lugar o $2^{\circ}$ Workshop de Gastronomia Molecular, destinado aos professores acompanhantes dos alunos participantes.

\section{Maria João Carvalho}

Organização das OQJ 2011 em Vila Real

\section{Semifinal das Olimpíadas de Quí- MICA JÚNIOR NO IST (LISBOA)}

Estavam inscritas 20 escolas com um total de 34 equipas, tendo comparecido 32 equipas de 19 escolas.

Após uma sessão de boas vindas num dos anfiteatros da Torre Sul (de Química), a prova iniciou-se pelas 11 horas e durou um pouco mais de uma hora, tendo sido montado um esquema rotativo das equipas agrupadas em 6 grupos, identificados pelas classes principais de elementos da Tabela Periódica. O conjunto de provas incluiu a realização de pequenas experiências e a resposta a questionários, colocados em laboratórios ou projectados em anfiteatros, sobre vários aspectos da química, incluindo personalidades relevantes para o progresso desta ciência e sobre a importância da química no dia-a-dia.

Após o merecido almoço, oferta da Reitoria da Universidade Técnica de

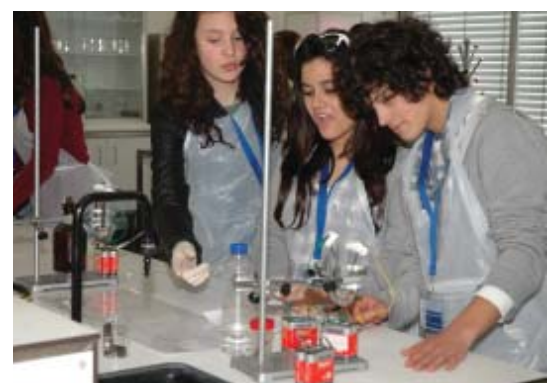

Ambiente vivido nas provas da Semifinal das OQJ na UTAD 
Lisboa, servido na cantina situada no IST, e com a generosa oferta do S. Pedro, alunos e professores puderam desfrutar de um curto período de lazer.

As actividades foram retomadas pelas $14 \mathrm{~h}$, tendo havido duas sessões de divulgação da química, já habituais nas realizações no IST: uma sobre a luz, sua origem, natureza e manifestações, apresentada pelos Prof. Manuel Prieto e Mário Nuno Berberan e Santos (Presidente da SPQ); e a segunda sobre azoto líquido e bolas de sabão, apresentada pela Prof. Clementina Teixeira, e que envolveu, como habitual, uma muito animada interacção com todos os participantes.
Pelas $16 \mathrm{~h}$ foram divulgadas as equipas vencedoras:

$1^{\circ}$ Lugar: Equipa "DABEST" da Escola Integrada São Bruno, constituída por Bernardo Reis, Dinis Costa e Ricardo Namora, e acompanhada pela Prof ${ }^{a}$ Rosa Lima Fernandes;

$2^{\circ}$ Lugar: Equipa "Stuart Carvalhais A" da Escola de Stuart Carvalhais, constituída por João Rato, Mariana Aguiar e Mariana Machado, acompanhada pela Prof ${ }^{a}$ Elsa Batalha;

$3^{\circ}$ Lugar: Equipa "CIS" do Colégio Infante Santo, constituída por António Gomes, Gabriela Duarte e Joana
Duarte, acompanhada pela Prof ${ }^{a}$ Ana Margarida Rebelo;

tendo então sido encerradas as actividades da edição de 2011 das OQJ no IST.

Agradecimentos aos colegas do IST envolvidos nas actividades e aos alunos, em particular aos alunos do Núcleo de Engenharia Química do IST, cujo apoio foi essencial. Mais ainda, um agradecimento em particular aos alunos e seus professores que entusiasticamente participaram nestas olimpíadas.

\section{Jorge Morgado}

Organização das OQJ 2011 em Lisboa

\section{Solvay \& Hovione Innovation Challenge 2011}

Foi assinado em Abril um protocolo de cooperação entre a SPQ e as empresas Solvay Portugal e a Hovione Farmacêutica para a promoção do Concurso Solvay \& Hovione Innovation Challenge 2011 (SHIC'11). O SHIC'11 surge na continuidade de uma iniciativa semelhante realizada em 2008 (SHIC'08), sendo na sua essência um concurso de ideias direccionado para o meio académico e centros de investigação que visa promover a inovação em Portugal, estabelecer as empresas Solvay e Hovione como parceiros activos e dinâmicos do meio académico português e distinguir ideias e projectos inovadores capazes de gerar mais valias nas áreas de Engenharia Química, Química, Materiais, Ambiente, Química Fina e Desenvolvimento Farmacêutico.

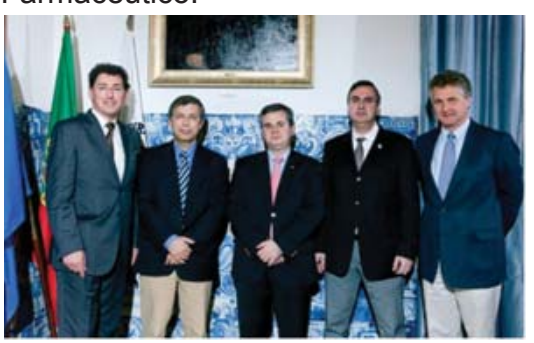

Representantes das empresas patrocinadoras e dos parceiros institucionais do Concurso SHIC'11 durante a cerimónia de celebração do protocolo de cooperação assinado a 19 de Abril na Reitoria

da Universidade Técnica de Lisboa. Ordem

da esquerda para a direita: Solvay Portugal

(Eng. Jorge Oliveira); Ordem dos Engenheiros

(Prof. Eugénio Campos Ferreira); Ordem dos

Farmacêuticos (Prof. Carlos Maurício Barbosa);

Sociedade Portuguesa de Química (Prof. Mário

Berberan e Santos); Hovione Farmacêutica (Dr.

Guy Villax); A Agência de Inovação não esteve representada na cerimónia
O concurso, cuja candidatura decorre até 16 de Setembro, conta com o apoio da Sociedade Portuguesa de Química, do Colégio de Engenharia Química e Biológica da Ordem dos Engenheiros, do Colégio de Especialidade em Indústria Farmacêutica da Ordem dos Farmacêuticos e da Agência de Inovação, entidades com as quais foram celebrados protocolos de colaboração. Serão atribuídos dois prémios de 10000 euros cada (5000 euros a título pecuniário e 5000 euros como financiamento imediato do projecto) e oportunidades de contactos privilegiados com a comunidade empresarial.

O concurso está aberto a projectos/ ideias inovadoras em duas plataformas, consistindo em dois prémios distintos:

- O Prémio Solvay (Engenharia Química, Química, Materiais e Ambiente), que premiará projectos geradores de ideias, produtos ou processos inovadores, preferencialmente nas áreas dos produtos de base inorgânica (designadamente, sais de sódio, cálcio, bário e estrôncio), electroquímica e química do cloro e flúor (de base orgânica ou inorgânica), peróxidos e detergência (designadamente, perboratos e percarbonatos), polímeros (essenciais e avançados), energias renováveis (componentes e novos materiais para aplicações baseadas em ener- gias renováveis), química sustentável e electrónica (novos materiais para aplicações em IT).

- O Prémio Hovione (Química Farmacêutica e Desenvolvimento Farmacêutico), que premiará projectos geradores de ideias, produtos ou processos inovadores, preferencialmente nas áreas da inovação na produção em batch, novos métodos na produção industrial de APIs (Active Pharmaceutical Ingredients), química verde com aplicação na produção de APIs, supergenéricos, engenharia de partículas, nanotecnologia e inalação pulmonar.

O concurso destina-se a docentes, investigadores e estudantes de universidades e institutos de investigação portugueses, devendo as candidaturas ser formalizadas online através do site www.shic2011.com. O júri de avaliação dos projectos em concurso será composto por dez elementos (cinco para cada prémio) dos quais farão parte um conjunto de personalidades de relevo do meio académico, representantes dos parceiros institucionais e representantes da Solvay e da Hovione. Os resultados serão divulgados em sessão pública prevista para Novembro.

Helder Gomes (bquimica@ipb.pt) www.spq.pt 